\title{
Role of thalamic projection in NMDA receptor-induced disruption of cortical slow oscillation and short-term plasticity
}

\author{
Tamás Kiss ${ }^{1}{ }^{*}$, William E. Hoffmann ${ }^{1}$, Liam Scott ${ }^{1}$, Thomas T. Kawabe ${ }^{1}$, Anthony J. Milici', Erik A. Nilsen ${ }^{2}$ \\ and Mihály Hajós ${ }^{1}$
}

1 Neuroscience Research Unit, Pfizer Global Research and Development, Pfizer Inc., Groton, CT, USA

2 Blackrock Microsystems, Salt Lake City, UT, USA

Edited by:

Anthony A. Grace, Yale University, USA

\section{Reviewed by:}

Patricio O'Donnell, University of

Maryland School of Medicine, USA

Daniel J. Lodge, University of Texas

Health Science Center in San Antonio,

USA

\section{*Correspondence:}

Tamás Kiss, Neuroscience Research Unit, Pfizer Global Research and Development, Pfizer Inc., Eastern Point Road, MS 8220-4335, Groton, CT 06340, USA.

e-mail: tamas.kiss@pfizer.com
NMDA receptor (NMDAR) antagonists, such as phencyclidine, ketamine, or dizocilpine (MK-801) are commonly used in psychiatric drug discovery in order to model several symptoms of schizophrenia, including psychosis and impairments in working memory. In spite of the widespread use of NMDAR antagonists in preclinical and clinical studies, our understanding of the mode of action of these drugs on brain circuits and neuronal networks is still limited. In the present study spontaneous local field potential (LFP), multi- (MUA) and single-unit activity, and evoked potential, including paired-pulse facilitation (PPF) in response to electrical stimulation of the ipsilateral subiculum were carried out in the medial prefrontal cortex (mPFC) in urethane anesthetized rats. Systemic administration of MK-801 $(0.05 \mathrm{mg} / \mathrm{kg}$, i.v.) decreased overall MUA, with a diverse effect on single-unit activity, including increased, decreased, or unchanged firing, and in line with our previous findings shifted delta-frequency power of the LFP and disrupted PPF (Kiss et al., 2011). In order to provide further insight to the mechanisms of action of NMDAR antagonists, MK-801 was administered intracranially into the MPFC and mediodorsal nucleus of the thalamus (MD). Microinjections of MK-801, but not physiological saline, localized into the MD evoked changes in both LFP parameters and PPF similar to the effects of systemically administered MK-801. Local microinjection of MK-801 into the mPFC was without effect on these parameters. Our findings indicate that the primary site of the action of systemic administration of NMDAR antagonists is unlikely to be the cortex. We presume that multiple neuronal networks, involving thalamic nuclei contribute to disrupted behavior and cognition following NMDAR blockade.

Keywords: MK-801, paired-pulse facilitation, local field potential, unit activity, medial prefrontal cortex, localized drug microinjection, subiculum, schizophrenia

\section{INTRODUCTION}

Schizophrenia has been linked to NMDA receptor (NMDAR) dysfunction by genetic, pharmacological, and imaging studies. Genes known to regulate glutamate and NMDAR function such as neuregulin, ERBB4, and dysbindin, have been shown to be affected in schizophrenia (Moghaddam, 2003; Harrison and Owen, 2003; Harrison and West, 2006). Abnormal glutamate metabolism has also been reported in schizophrenic patients (Tsai et al., 1995), however imaging studies have yielded conflicting results about brain glutamate levels. Increased glutamate levels in the left dorsolateral prefrontal cortex (Olbrich et al., 2008), left thalamus (Théberge et al., 2003), prefrontal cortex, and hippocampus (van Elst et al., 2005), as well as decreased levels of glutamate in left anterior cingulate cortex (Théberge et al., 2003) and the mesial prefrontal cortex (Lutkenhoff et al., 2010) have been described in schizophrenia patients.

In support of the NMDAR dysfunction hypothesis of schizophrenia, NMDAR antagonists have been shown to produce psychosis and schizophrenia-like cognitive deficits (Krystal et al., 1994; Lahti et al., 1995b; Newcomer et al., 1999; Javitt et al., 2008) in healthy human subjects. Similar to responses seen in humans, NMDAR antagonist evoke sensory, behavioral, and cognitive dis- turbances in non-human primates (Taffe et al., 2002; Buccafusco and Terry, 2009; Roberts et al., 2010a,b,c), therefore these pharmacological agents have become widely used to model various symptoms of schizophrenia in preclinical experiments. However, the precise mechanism and site of action of NMDAR antagonists still are not fully understood (for reviews see: Gunduz-Bruce, 2009; Gruber et al., 2010; Kantrowitz and Javitt, 2010; Marek et al., 2010).

Some recent cognitive and electrophysiological studies suggest that principal pyramidal neurons and/or interneurons of the medial prefrontal cortex (mPFC) are the primary targets of systemic administration of NMDAR antagonists (Jackson et al., 2004). In a previous work (Kiss et al., 2011) we studied effects of systemic administration of the NMDAR antagonist MK-801 on the oscillatory activity of the MPFC and its response to electrical stimulation of the subiculum in urethane anesthetized rats. Findings demonstrated that MK-801 significantly modulates cortical delta band activity and abolishes short-term plasticity in the mPFC. In the present study we have made further efforts to characterize this NMDAR dysfunction model by analyzing parallel single-unit activity and field potential recordings as well as using localized microinjections to identify brain regions where MK-801 may exert its primary action. 


\section{MATERIALS AND METHODS}

\subsection{ANIMALS AND SURGICAL PROCEDURES}

Experiments were performed on male Sprague-Dawley rats (Harlan, Indianapolis, IN, USA; weighing 250-320 g) under urethane anesthesia (1.5 g/kg, i.p.). Surgical procedures were conducted in accordance with an approved animal use protocol in compliance with the Animal Welfare Act Regulations and with the Guide for the Care and Use of Laboratory Animals, National Institutes of Health guidelines. The femoral vein was cannulated for administration of drugs. The anesthetized rat was placed in a stereotaxic frame, and craniotomies were performed above the region of the mPFC and ipsilateral CA1/subiculum. Body temperature of the rat was maintained at $37^{\circ} \mathrm{C}$ by means of a thermostatically controlled electrical heating pad (Harvard Apparatus). After conclusion of experiments animals were euthanized with an i.v. bolus of urethane.

\subsection{ELECTROPHYSIOLOGICAL RECORDINGS}

Local field potentials (LFPs) were recorded from 36 rats using a metal monopolar macroelectrode placed into the $\mathrm{mPFC}$ region (co-ordinates: $3.0 \mathrm{~mm}$ anterior from bregma, $0.6 \mathrm{~mm}$ lateral,
$5.0 \mathrm{~mm}$ ventral; Paxinos and Watson, 1986; see Figure 1). Five rats were implanted with an electrode in both mPFCs (co-ordinates are the same as above) to characterize bilateral effects of localized MK-801 microinjections into the mediodorsal nucleus of the thalamus. All animals were allowed to stabilize for $30 \mathrm{~min}$ following electrode and cannula placement. Field potentials were amplified, filtered $(0.1-100 \mathrm{~Hz})$, displayed, and recorded at $1 \mathrm{kHz}$ sampling rate for online and offline analysis (Spike2 software, version 7.01, Cambridge Electronic Design Ltd, UK).

Multi-site recordings were performed in six rats using singleshank silicon probes (NeuroNexus Technologies), with 16 linearly arranged recording sites at $100 \mathrm{~mm}$ intervals implanted at the same location as the monopolar macroelectrodes in the other set of experiments (see above). For single-unit measurement signals were amplified, high-pass filtered $(700 \mathrm{~Hz})$, and recorded at $30 \mathrm{kHz}$ sampling rate (Blackrock Microsystems). Firing threshold was set to: $-5 \cdot \mu_{1 / 2}(\mid x / / 0.6745)$ where $x$ is the high-pass filtered signal and $\mu_{(1 / 2)}$ denotes the median (Quiroga et al., 2004). Spike waveforms were digitally stored when the signal crossed firing threshold.

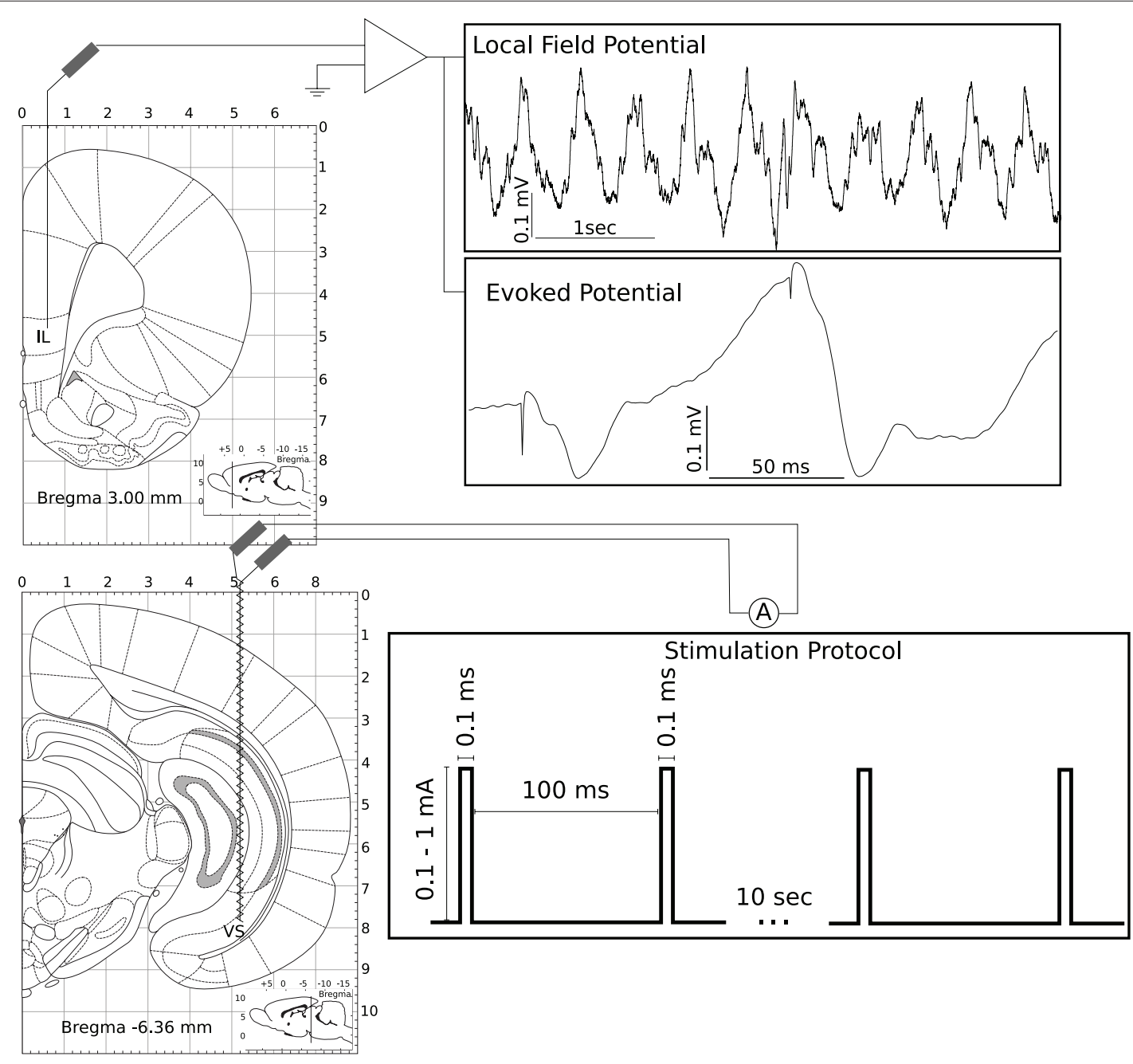

FIGURE 1 | Experimental protocol for paired-pulse stimulation of the subiculum. For a detailed description see Section 2. 


\subsection{PAIRED-PULSE STIMULATION}

Parallel to LFP measurements a twisted-wire stimulation electrode was placed in the CA1/subiculum (co-ordinates: $6.3 \mathrm{~mm}$ posterior from bregma, $5.2 \mathrm{~mm}$ lateral, and $8.0 \mathrm{~mm}$ ventral; Paxinos and Watson, 1986) of all rats in this study. The paired-pulse stimulus consisted of two square-pulses, duration $0.1 \mathrm{~ms}$, amplitude $0.1-1 \mathrm{~mA}$, paired-pulse interval $100 \mathrm{~ms}$, inter-stimulus interval $10 \mathrm{~s}$, generated continuously from a Master 8 stimulator (APMI, USA). Intensity of the stimulus was adjusted so that the first evoked response amplitude was $\approx 100 \mu \mathrm{V}$ (Figure 1).

\subsection{LOCALIZED MK-801 MICROINJECTION}

In addition to the recording and stimulating electrodes placed in the ventral mPFC and ipsilateral subiculum of the hippocampus respectively, a 30 gage stainless steel cannula was placed in both the ipsi- and contralateral mPFCs (co-ordinates from bregma: $3.4 \mathrm{~mm}$ anterior, $0.6 \mathrm{~mm}$ lateral, $5.0 \mathrm{~mm}$ ventral; Paxinos and Watson, 1986) in four animals, or in the ipsilateral mediodorsal thalamic nucleus (MD; co-ordinates from the bregma: $2.3 \mathrm{~mm}$ posterior, $0.8 \mathrm{~mm}$ lateral, and $6.0 \mathrm{~mm}$ ventral; Paxinos and Watson, 1986) in five animals for localized infusion of MK-801, and in four animals for saline control. Baseline cortical LFP activity, and corresponding evoked response amplitudes were recorded bilaterally using macroelectrodes (see Section 2.2). Animals were subsequently infused with $1 \%$ MK-801 (in saline). A microdialysis infusion pump (WPI SP101i) and a 250- $\mu$ l Hamilton syringe were used to infuse at the rate of $1 \mu \mathrm{l} / \mathrm{min}$. Details of infusions are described in Sections 3.3 and 3.4.

\subsection{HISTOLOGICAL PROCESSING}

After animals were euthanized at conclusion of electrophysiology experiments, brains were rapidly removed and frozen fresh on dry ice. Brains were sliced into $20 \mathrm{~mm}$ sections at $-18^{\circ} \mathrm{C}$ using a microtome and mounted on $25 \mathrm{~mm} \times 75 \mathrm{~mm} \times 1 \mathrm{~mm}$ microscope slides. Sections were fixed for $5 \mathrm{~min}$ in $4 \%$ paraformaldehyde, rinsed in $\mathrm{dH}_{2} \mathrm{O}$, then stained with $0.5 \%$ Cresyl Echt Violet for Nissl substance. The slides were then rinsed in $\mathrm{dH}_{2} \mathrm{O}$, dehydrated, cleared in xylene, and coverslipped. Slides were scanned in Aperio ScanScope XT (Aperio Technologies Inc. Vista, CA, USA) at 10×.

\subsection{DATA ANALYSIS}

\section{LFP and PPF}

Electrically evoked responses and quantitative EEG analysis were performed by means of waveform averages and Fast Fourier Transformation, respectively. For offline data analysis, LFP data was read into the MATLAB software [The Mathworks, Natick, MA, USA, version 7.8 (R2009a)] using the sigTOOL toolbox (Lidierth, 2009). For data epoching, filtering, and time-frequency decomposition, the EEGLAB Matlab toolbox (Delorme and Makeig, 2004) was used, while other operations were carried out by custom made scripts. Delta power spectrum density of the LFP was calculated between 0.1 and $4 \mathrm{~Hz}$. Paired-pulse facilitation (PPF) was defined as the ratio of the amplitude of the first evoked response (P1) and the second evoked response (P2). Experiments where the PPF in control was less than 1.5 were rejected from the analysis.

\section{Cellular activity}

Spikes were automatically sorted offline using the Spike 2 software. Automatic cluster cutting was manually adjusted. Autocorrelograms for each cluster were calculated with $0.5 \mathrm{~ms}$ binning of events to set up criteria for including a cluster in subsequent analysis (Harris et al., 2000). We used the $\left\langle N_{1: 2}\right\rangle<0.02^{*}\left\langle N_{950: 1000}\right\rangle$ rule, where $N_{x}$ is the value for the $x$ th bin of the autocorrelogram, and $\left\langle N_{x: y}\right\rangle$ denotes averaging bins from $x$ to $y$, which selected only sufficiently clean clusters. For firing rate analysis, number of spikes emitted by each cell was counted in 1 min long bins in baseline condition and after MK-801 administration. Determination of whether a cell's firing rate increased, decreased, or did not change was made by comparing binned spike numbers by two-sample, two-tailed $t$-tests. To characterize burstiness inter-spike interval histograms were computed and spikes occurring within $20 \mathrm{~ms}$ were counted. To establish whether burstiness of a cell increased or decreased following MK-801 administration the method described for firing rate calculation was used.

Statistical analysis was carried out in Matlab (Statistics Toolbox, version 7.1) or in R (R Development Core Team, 2008).

\section{RESULTS}

In line with our previous experiments (Kiss et al., 2011) we have shown that in urethane anesthetized rats, spontaneous LFP recorded from the mPFC mainly consists of a large amplitude (peak-to-peak $\approx 0.5 \mathrm{mV}$ ), regular, $\approx 2 \mathrm{~Hz}$ frequency oscillation termed high-delta (1.5-2.5 Hz band) oscillation (Figure 2). Electrical stimulation of the ipsilateral subiculum evokes a response with approximately $25 \mathrm{~ms}$ latency (Figure 3B, left), and a second pulse, delivered 100 ms later evokes a second, approximately three times bigger response with similar, but not identical temporal characteristics. This enhancement of response amplitude is termed PPF.

Systemic administration of MK-801 ( $0.05 \mathrm{mg} / \mathrm{kg}$, i.v.), a non-competitive, use-dependent NMDAR antagonist significantly changed cortical EEG delta activity by increasing its amplitude and reducing its frequency into the 0.5 to $1.5-\mathrm{Hz}$ frequency range, termed here as low-delta oscillation (Figure2). Furthermore, the amplitude distribution of the spontaneous LFP changed from a symmetrical to a skewed distribution (c.f. insets on Figure 3A left and right). Concomitantly, MK-801 significantly reduced PPF primarily by increasing the amplitude of the first evoked response (c.f. Figures $3 \mathrm{Ca}, \mathrm{Cc}$ ).

\subsection{SYSTEMIC ADMINISTRATION OF MK-801 REDUCES PPF BY MULTIPLE EFFECTS, INCLUDING MODIFICATION OF ONGOING ACTIVITY}

To better characterize factors contributing to the above changes following systemic administration of MK-801, and to enable us to speculate about the cellular and network mechanisms underlying the generation of PPF of responses evoked by stimulating the subiculum, we further analyzed separate parts of the evoked field potentials.

Firstly, in control condition, we found that amplitude of the response evoked by the first stimulus (P1) tends to be larger, when stimulation coincided with high LFP values $\left(\mathrm{LFP}_{\Theta_{\mathrm{S} 1}}\right)$. For this, raw traces were transformed to zero mean, unity variance time series, and individual responses where $\mathrm{LFP}_{\oplus_{\mathrm{Sl}}} \leq 0 \mathrm{mV}$ and responses where $\mathrm{LFP}_{\varrho_{s 1}}>0 \mathrm{mV}$ were separately averaged and the two resulting responses compared to show a significant difference between first responses in the two averages $\left(\mathrm{Pl}_{\text {control }}^{\text {high }}\right.$ and $\mathrm{Pl}_{\text {control }}^{\text {low }}$; 


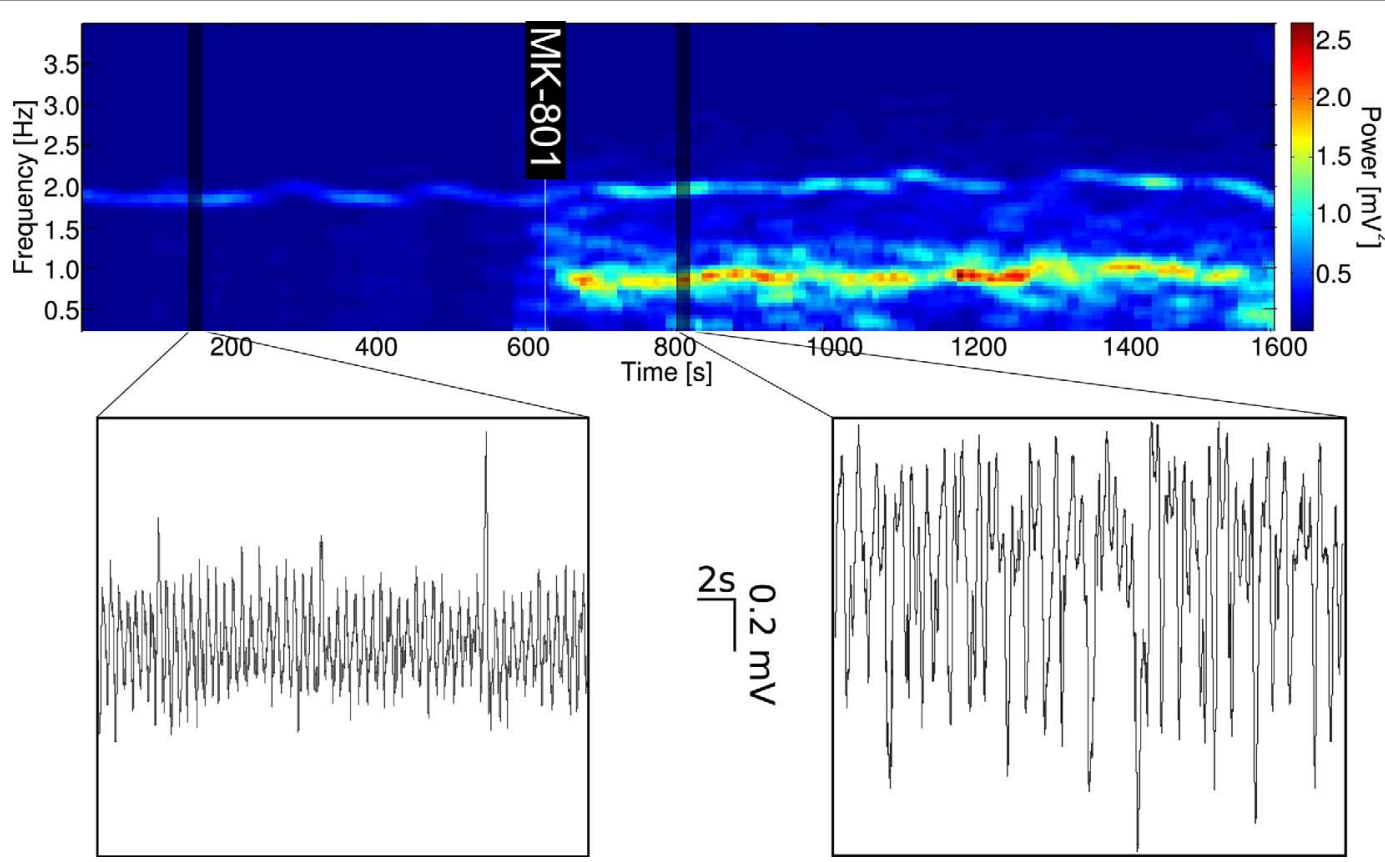

FIGURE 2 | Effect of systemic administration of MK-801 (0.05 mg/ $\mathrm{kg}$, i.v.) on field potential oscillations in the medial prefrontal cortex. Before drug administration the LFP is characterized by a regular, approximately $2 \mathrm{~Hz}$ frequency, $0.5 \mathrm{mV}$ amplitude rhythm, termed high-delta oscillation. Effects of systemic MK-801 administration include increasing the power of a lower frequency, less regular, larger amplitude oscillation (low-delta oscillation), and consequently decreasing relative high-delta power. A representative timefrequency plot and two, $30 \mathrm{~s}$ long LFP traces are shown.

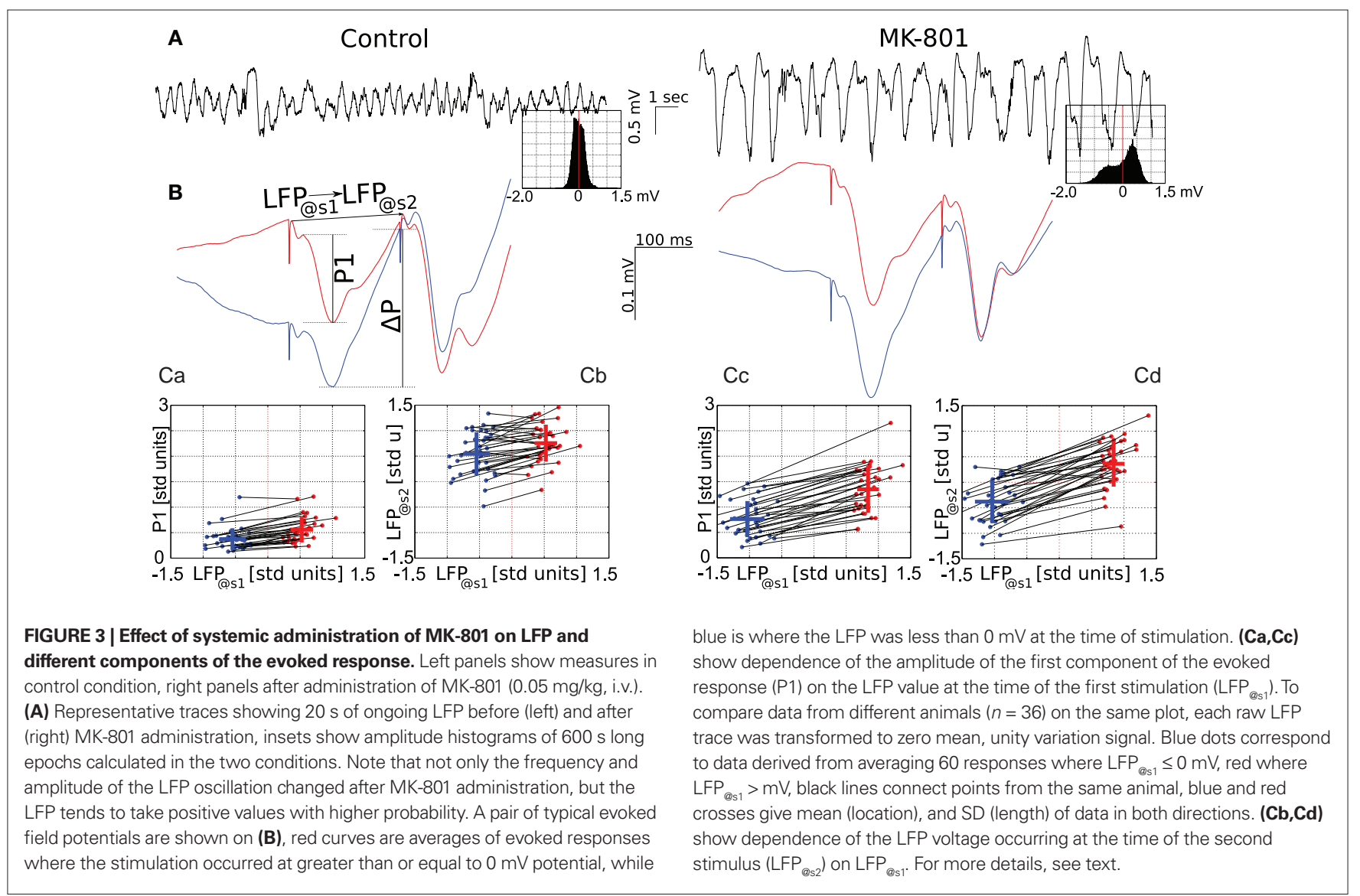


paired, two-tailed $t$-test: $p=7.4 \cdot 10^{-9}, 5 \%$ confidence interval for $\left\langle P 1_{\text {control }}^{\text {high }}-P 1_{\text {control }}^{\text {low }}\right\rangle=[0.140 .23]$; Figure $\left.3 \mathrm{Ca}\right)$. Systemic MK-801 administration increases the probability of high LFP values (Figure 3A, right panel inset), thus by modifying the ongoing oscillation, MK-801 increases the possibility to evoke larger first responses, and as a result decreased PPF. Moreover, besides this indirect effect, MK-801 also exerts a direct effect on the first response. Comparing average first response amplitudes of control and MK-801 groups, a significant difference was found in both high and low cases (paired, two-tailed $t$-test: $\left\langle\mathrm{P} 1_{\mathrm{MK}-801}^{\text {low }}-\mathrm{P} 1_{\text {control }}^{\text {low }}\right\rangle=[0.330 .58], 5 \%$ confidence interval, $p=2.7 .10^{-8},\left\langle\mathrm{P} 1_{\mathrm{MK}-801}^{\text {high }}-\mathrm{P} 1_{\text {control }}^{\text {high }}\right\rangle=[0.641 .03], 5 \%$ confidence interval, $p=2 \cdot 7 \cdot 10^{-8}$, cf. Figures $\left.3 \mathrm{Ca}, \mathrm{Cc}\right)$.

Secondly, calculating the difference $(\Delta P)$ between the potential at the trough of the first response and the potential at the time of the second stimulation ( $\mathrm{LFP}_{@_{\mathrm{s} 2}}$; see also Figure 3B, left) sheds some light at processes taking place in re-polarization of stimulated cells. In control condition, $\Delta P$ depends heavily on $\mathrm{LFP}_{@_{\mathrm{s} 1}}\left(\Delta P^{\text {high }}=0.8 \pm 0.4 \mathrm{mV}\right.$; $\left.\Delta P^{\text {low }}=1.4 \pm 0.4 \mathrm{mV}\right)$. Importantly, as re-polarization after deeper polarization is faster than after shallower polarization, by the time of the second stimulus, the LFP reaches similar values in both high and low cases (paired, two-tailed $t$-test: $p=7.9 \cdot 10^{-7}, 5 \%$ confidence interval for $\left\langle\operatorname{LFP}_{@_{\mathrm{s} 2} \text {,control }}^{\text {high }}-\mathrm{LFP}_{@_{\mathrm{S} 2 \text {, control }}^{\text {low }}}\right\rangle=\left[\begin{array}{ll}0.08 & 0.16\end{array}\right]$; Figures 3B,Cb). Interestingly enough, after MK-801 administration the corresponding potential differences are not changed significantly $\left(\Delta \mathrm{P}_{\text {control }}^{\text {high }} \approx \Delta \mathrm{P}_{\mathrm{MK}-801}^{\text {high }}\right.$ and $\Delta \mathrm{P}_{\text {control }}^{\text {low }} \approx \Delta \mathrm{P}_{\mathrm{MK}-801}^{\text {low }}$, paired, two-tailed $t$-test at $5 \%$ significancelevel). As the first pulse islarger after MK-801 as discussed above, this resultsin significantlylowerLFP ${ }_{\Theta_{52}}$ values compared to control $\left(p=2.7 \cdot 10^{-13},\left\langle\mathrm{LFP}_{@_{\mathrm{s} 2} \text {, control }}^{\text {low }}-\mathrm{LFP}_{@_{\mathrm{s} 2}, \mathrm{MK}-801}^{\text {low }}\right\rangle=[0.61 .1] ; \mathrm{p}=1.2 \cdot 10^{-16}\right.$, $\left\langle\mathrm{LFP}_{\Theta_{\mathrm{s} 2} \text {,control }}^{\text {high }}-\mathrm{LFP}_{\Theta_{\mathrm{s} 2}, \mathrm{MK}-801}^{\text {high }}\right\rangle=[0.260 .53]$; cf. Figures $\left.3 \mathrm{Cb}, \mathrm{Cd}\right)$. Thus by modifying the ongoing oscillatory state, MK-801 modifies the environment in which both the first and the second stimulus are delivered, which in turn results in decreased PPF and ultimately, altered information processing.

\subsection{SYSTEMIC ADMINISTRATION OF MK-801 RESULTS IN DECREASED SPIKING ACTIVITY}

A group of six rats were implanted with multi-site silicone electrodes to record cellular activity in the $\mathrm{mPFC}$. Comparing the total number of spikes [multi-unit activity (MUA)] recorded in a 10-min long period before and $5 \mathrm{~min}$ after systemic MK-801 administration $(0.05 \mathrm{mg} / \mathrm{kg}$, i.v. $)$ revealed a significant decrease of spiking activity (Figure 4A; two-sample, two-tailed $t$-test, $p=0.0128,5 \%$ confidence interval for $\left\langle\mathrm{MUA}_{\text {baseline }}-\mathrm{MUA}_{\mathrm{MK}-801}\right\rangle=[0.090 .75]$ spikes/s).

Besides measuring MUA, a total of 148 cells were clustered from these recordings. Clustering spikes revealed, that although the overall spiking activity decreases, individual cells activity (Figures 4B-D) decrease $[n=66(44.6 \%)]$, increase $[n=30(20.3 \%)]$, or remain unchanged $[n=52(35.1 \%)]$. Furthermore, changes in burstiness was also evaluated. We found that 15 cells $(10.1 \%)$ had decreased, 25 cells $(16.9 \%)$ had increased, and 108 (73.0\%) had unchanged burstiness based on our definition (see Section 2.6).

\subsection{MICROINJECTIONS OF MK-801 LOCALIZED IN THE mPFC DO NOT EFFECT DELTA-FREQUENCY LFP OSCILLATION OR PPF}

Our next efforts targeted the localization of the site of action of MK-801. We first tested whether local microinjection into the mPFC evokes the electrophysiological effects observed after systemic MK-801 administration. For this experiment four rats were implanted with two cannulae, one in the ipsi- and an other in the contralateral mPFC (relative to the recording site) for local infusion of MK-801. After a 5-min baseline period MK-801 was injected into the ipsilateral side by a microdialysis pump at $1.0 \mu \mathrm{l} /$ min rate for 5 or $10 \mathrm{~min}$, resulting in the injection of 50 or $100 \mathrm{mg}$ of MK-801. Following an approximately $5 \mathrm{~min}$ long delay a second injection of MK-801 was delivered into the contralateral mPFC using the same parameters as that of the ipsilateral mPFC injection. LFP and evoked responses were recorded.

Figure 5A shows a spectrogram calculated from a representative LFP recorded during $\mathrm{mPFC}$ injection. Changes in ongoing oscillations relative to baseline were not observed at any time or treatment domain. This was further confirmed by calculating the ratio of power contained in the 1.5 to $2.5-\mathrm{Hz}$ range (high-delta interval) to the total power in baseline condition, after ipsilateral injection of MK-801, and after bilateral injection, respectively. A one-way ANOVA did not show significant differences between groups $(p=0.101$; Figure 5B). Similarly, P1 and P2 components, as well as PPF of responses evoked by stimulation of the subiculum did not change significantly (one-way ANOVA for PPF: $p=0.352$; Figure 5C; for the first response amplitude: $p=0.255$; for the second response: $p=0.302$ ). To ensure potency of the used MK-801 solution, a group of rats were injected intravenously and the previously described systemic effects were seen (data not shown).

\subsection{LOCALIZED MK-801 INJECTION INTO THE MEDIODORSAL NUCLEUS OF THE THALAMUS HAS SIMILAR EFFECTS TO SYSTEMIC MK-801 ADMINISTRATION}

Effects of systemic administration of MK- 801 are characterized by specific changes in delta oscillation (Figure 2, also see Kiss et al., 2011). It is presumed that cortical delta rhythm has two different sources, one originating in the neocortex (Amzica and Steriade, 1998), the other in the thalamus (Steriade et al., 1993). Our previous findings (Kiss et al., 2011) showed that blocking action potential generation in the mediodorsal nucleus of the thalamus by local lidocaine microinjections reproduced changes evoked by systemic MK-801 administration. Localized MK-801 microinjections into the mediodorsal nucleus of the thalamus (Figure 6) evoked similar effects to those seen after intravenous MK-801 administration or localized lidocaine microinjection. MK-801 injection localized to the $\mathrm{MD}$ resulted in a significant decrease of relative high-delta power on the ipsilateral side and a trend to decrease on the contralateral side in the mPFC (Figure 7D). These changes in high-delta are accompanied by an increase in absolute (Figure 7A) and relative low-delta power (Figure 8A). Local MD injection of MK-801 significantly increased the $\mathrm{P} 1$ component of the evoked response without increasing the P2 component (Figure 7B; paired $t$-test, $p=0.0499$, $5 \%$ confidence interval for $\left\langle\mathrm{PI}_{\mathrm{MD} \text { injection }}-\mathrm{PI}_{\text {Baseline }}\right\rangle=\left[\begin{array}{l}20.67129 .35\end{array}\right]$ $\mu \mathrm{V})$. PPF in all animals decreased after drug administration, however significance was not reached (paired $t$-test $p=0.1705$ ) due to big variation within baseline values (Figure 7C).

In contrast, physiological saline injection into the MD failed to reproduce changes seen after MK-801 administration $(n=4)$. Spectrograms calculated from ipsilateral mPFC LFPs did not show the characteristics observed after systemic or MD-localized MK-801 administration, although a small but significant decrease 
A
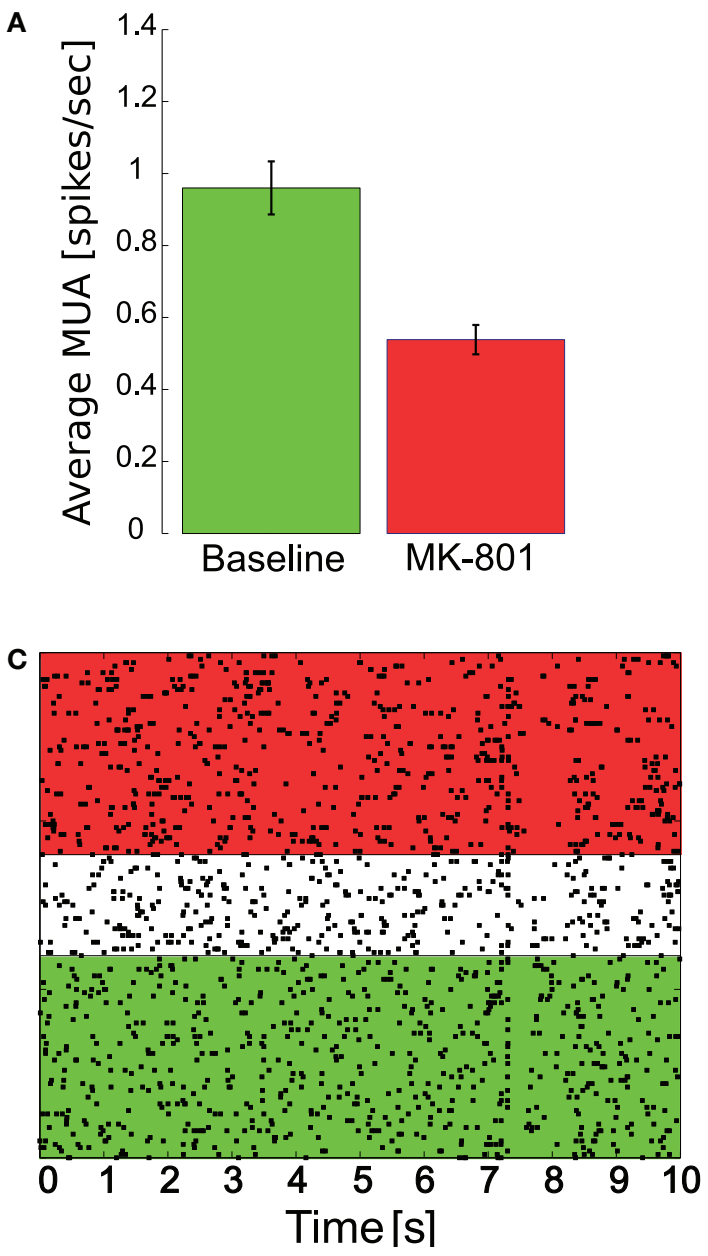

FIGURE 4 | Change of cellular activity in response to MK-801 administration. Multi-unit activity (A), reflecting an average change of spiking activity showed a significant ( $p=0.0128$ ) decrease (mean \pm SEM shown) following drug treatment (0.05 mg/kg MK-801, i.v.), however, individual cells with decreased (B),
B

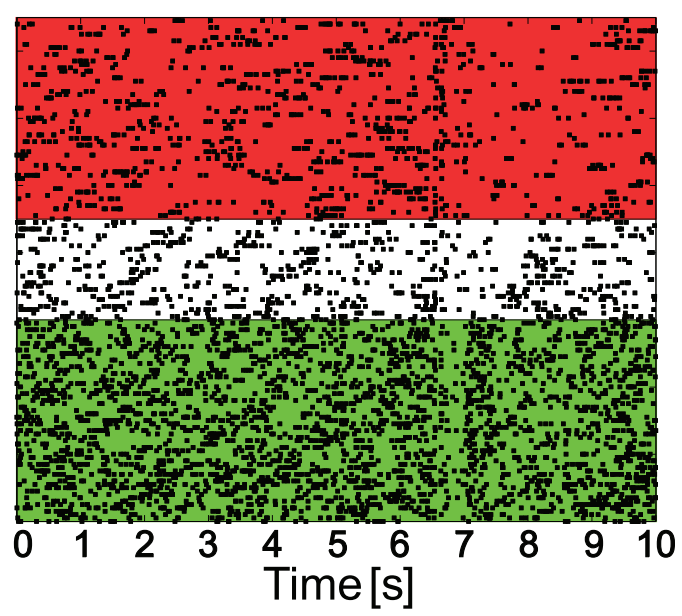

D

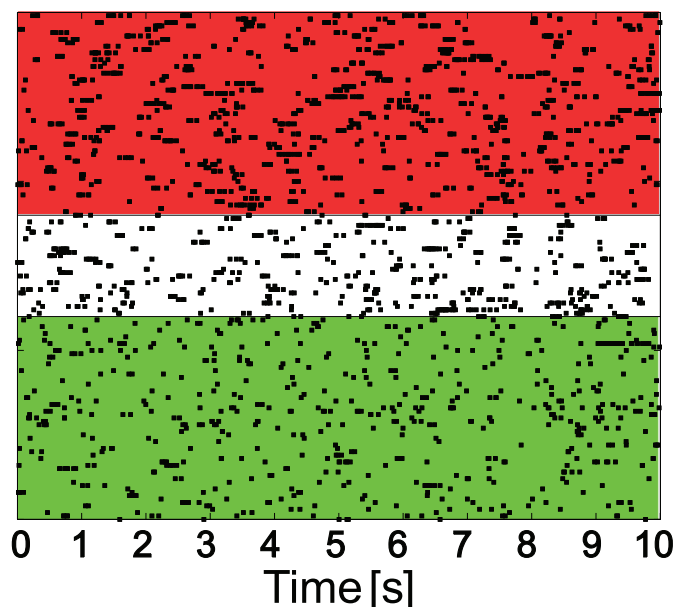

unchanged (C), or increased (D) firing activity were found. (B-D) show raster plots of individual cells (baseline spike counting period is highlighted in green, MK-801 was given at the beginning of the white period, which was 5 min long, spikes for MK-801 treatment were counted in the region highlighted in red). in high-delta component in these experiments was observed (Figures 9A,D). However, when compared to MK-801 administration, saline evoked a significantly smaller decrease in power in this frequency band (Figure 8B). This small decrease of cortical high-delta power might be a result of non-drug related effects of microinjection such as changes in brain temperature, changes in ionic concentration of the interstitial matrix or increased extracellular pressure. Furthermore, no change was observed in parameters of the evoked responses following saline injection into $\mathrm{MD}$ (Figures 9B,C).

\section{DISCUSSION}

The present findings demonstrate that systemic administration of the NMDAR antagonist MK-801 in anesthetized rats changes regular cortical field potential oscillation by altering power distribution within the delta band and modifies firing activity of the majority of cortical neurons. Parallel to changes in cortical delta oscillation, MK-801 also decreases short-term plasticity as indicated by a reduction in PPF of the cortical response elicited by stimulation of the subiculum. Detailed analysis of the relationship between field potential changes and reduction in PPF revealed that multiple mechanisms contribute to decreased PPF; one of the significant contributing factors is a skewed distribution of positive-negative values in field potentials after MK-801. Furthermore, effects of systemic administration of MK-801 has been reproduced by local microinjection of the drug into the mediodorsal nucleus of the thalamus, but not the mPFC, indicating that effects of non-competitive NMDAR antagonists on cortical function involve complex neuronal circuitry mechanisms.

A large body of literature suggests that the mPFC is a key region involved in the expression of pathological behavior and impairment of cognitive functions, such as working memory, in schizophrenic patients (Winn, 1994; Knable and Weinberger, 1997). NMDAR antagonists phencyclidine (PCP) and ketamine, which are capable of evoking cognitive deficits in healthy volunteers similar to schizophrenic patients (Luby et al., 1959; Krystal et al., 1994; Malhotra et al., 1996), have been shown to primarily affect activity of the PFC (Lahti et al., 1995a; Breier et al., 1997). Animal models using 

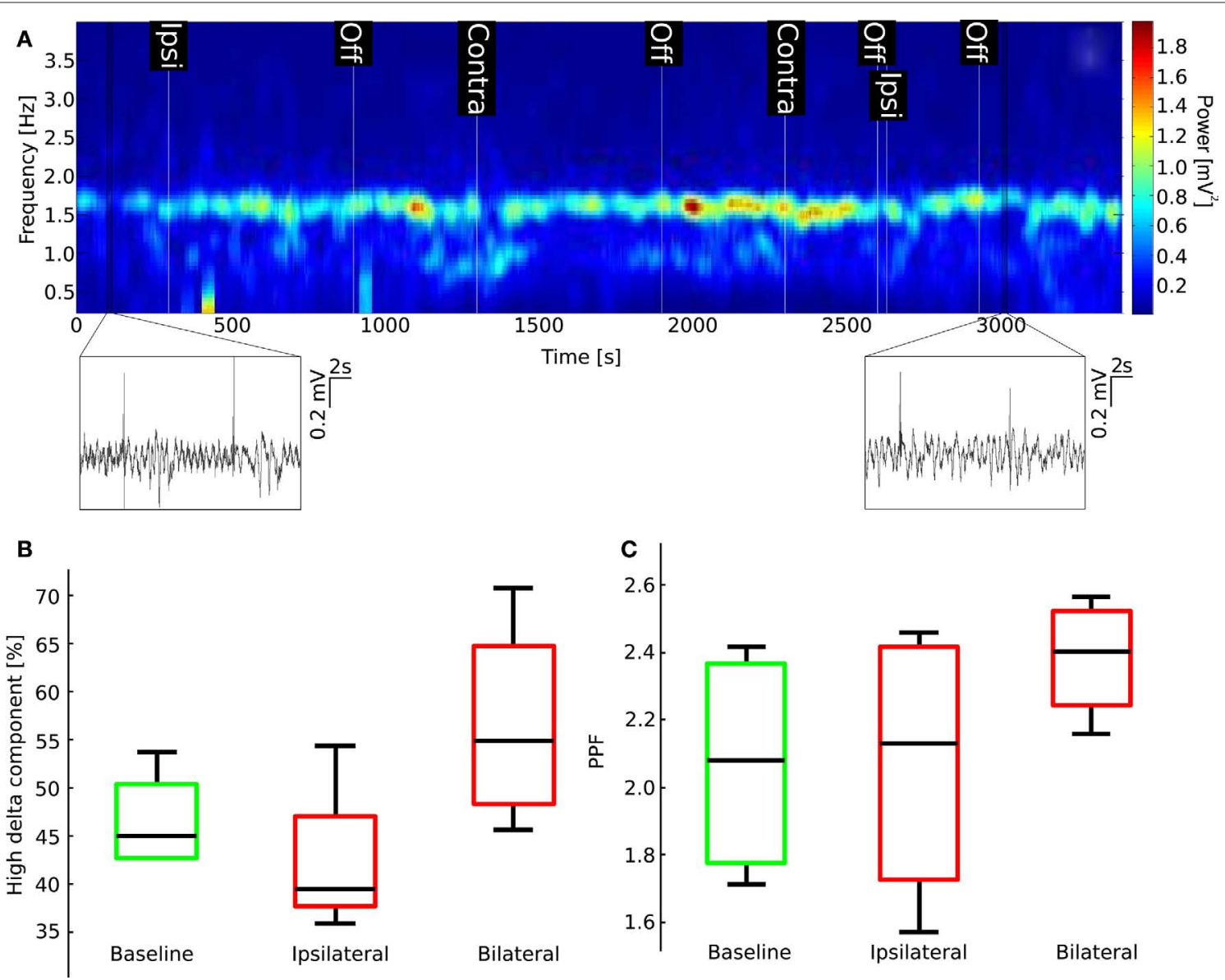

FIGURE 5 | Localized bilateral administration of MK-801 into the mPFCs does not have effects on LFP oscillations or PPF. (A) Spectrogram for a representative experiment does not show the characteristic appearance of a strong low-delta component characteristic of systemic MK-801 injection (cf.

Figure 2; insets show two 20 s long LFP traces from the shown region of the

recording, each including two stimulation periods). (B) Boxplot of relative high-delta-frequency component of the power spectrum (middle black bar is median, green (baseline), and red (MK-801) boxes show 25th and 75th percentiles, whiskers are most extreme data points). (C) Boxplot representing changes in PPF.

NMDAR antagonists induce sensory (Mansbach and Geyer, 1989; Miller et al., 1992), behavioral (Freed et al., 1980; Moghaddam and Adams, 1998; Jentsch and Roth, 1999), and cognitive (Heale and Harley, 1990; Verma and Moghaddam, 1996) disturbances some of which involve the mPFC - that resemble schizophrenia symptoms. Thus, several studies have focused on identifying the precise mechanism localized within the $\mathrm{MPFC}$, through which NMDAR antagonists disrupt function of this brain region (Sebban et al., 2002; Lorrain et al., 2003; Jodo et al., 2005; Homayoun and Moghaddam,2007; Kargieman et al., 2007). However, studies using microinjections of NMDAR antagonists into the mPFC are not conclusive about its effectiveness. For example, in a series of studies Suzuki et al. (2002) were unable to reproduce the long-lasting activation of $\mathrm{mPFC}$ and augmented locomotion induced by systemic administration of PCP with direct injection of PCP into the mPFC.

Our findings demonstrate significant changes in activity of the $\mathrm{mPFC}$ in response to systemic administration of MK-801 in urethane anesthetized rats. In line with our previous observations (Kiss et al., 2011), MK-801 decreased regular oscillatory activity in the 1.5 to $2.5-\mathrm{Hz}$ delta band as reflected by a decrease in relative power in this frequency range and an increase in relative power in the 0.5 to $1.5-\mathrm{Hz}$ lower delta band. This change in delta power seems to be one of the mechanisms underlying the simultaneous reduction in PPF. Furthermore, alteration in relative power in delta band activity led to a right-skewed field potential distribution, indicating a more hyperpolarized membrane potential of cortical neuronal network. In accordance with this hypothesis, our present findings reveal that parallel to changes in field potential MK-801 decreased overall neuronal firing activity. Although the average firing rate of all recorded neurons in the $\mathrm{mPFC}$ was reduced, individual neurons showed varied responses to MK-801, including increased, decreased, or unchanged firing rate.

The most widely accepted hypothesis on MK-801-induced changes in cortical neuronal activity is based on observations obtained from recordings of cortical neurons in freely moving rats. Systemic administration of MK-801 has been reported to increase activity of presumed pyramidal neurons by reducing activity of GABAergic interneurons (Homayoun and Moghaddam, 2007). These observations are in line with a notion that NMDAR antagonists preferentially block NMDARs on interneurons, particularly those 


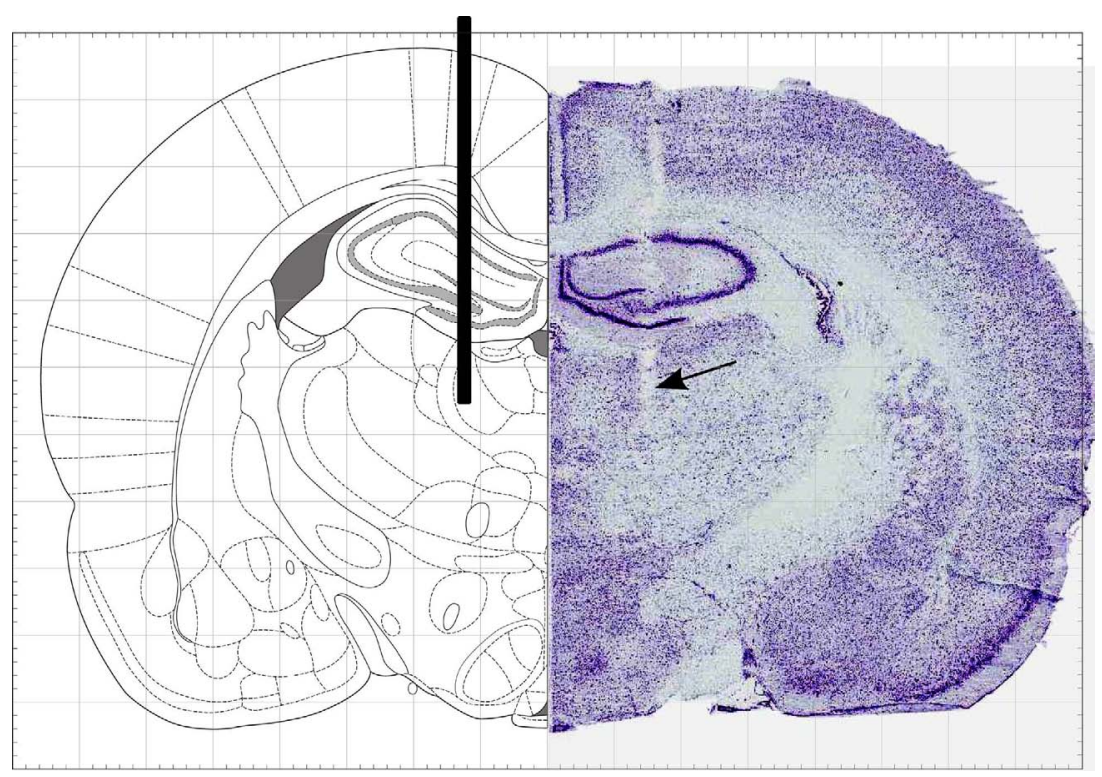

FIGURE 6 | MD cannula location. Stereotaxic diagram (left) and histological reconstruction (right) of the injection cannula (shown as a black bar on left) targeting the mediodorsal nucleus of the thalamus.

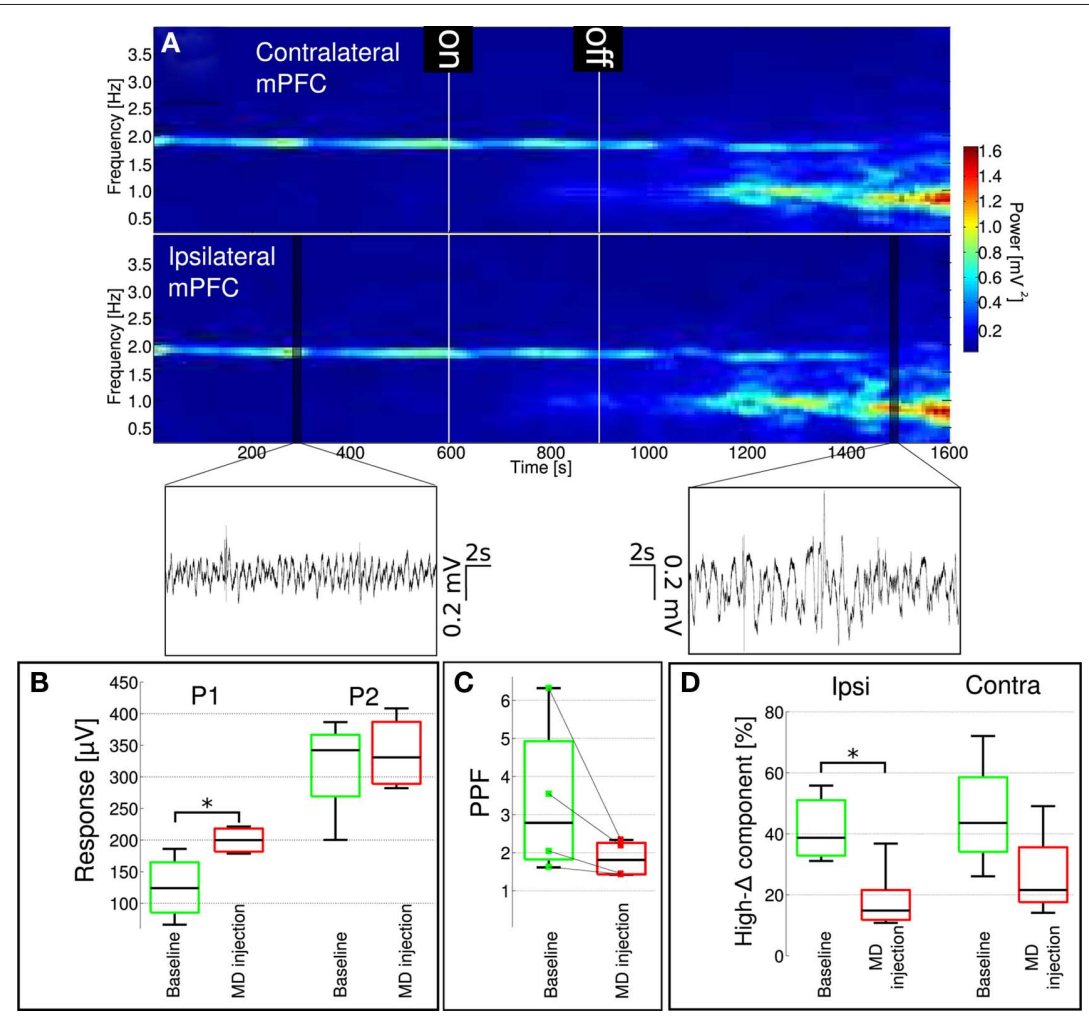

FIGURE 7 | Localized administration of MK-801 into the mediodorsal nucleus of the thalamus results in changes similar to those observed following systemic drug administration. (A) Spectrogram of contralateral (upper) and ipsilateral (lower) mPFC LFP. Microdialysis pump was turned on after $10 \mathrm{~min}$ baseline recording for $5 \mathrm{~min}$. Onset of activity similar to i.v. MK-801 injection was shortly after the pump was turned off in this particular experiment. Insets show characteristic LFP traces from highlighted regions of the ipsilateral signal.
(B) Similar to systemic MK-801 administration, P1 component of the evoked response increased significantly after MD microinjection $(p=0.0218)$, while $\mathrm{P} 2$ did not change significantly. (C) PPF showed a tendency to decrease, but changes did not reach significance (individual animal data also shown). Ongoing LFP delta oscillation (D) changed similar to systemic MK-801 administration: the relative high frequency delta component significantly decreased $(p=0.0499)$ in the ipsilateral mPFC, and showed a tendency to decrease $(p=0.1761)$ in the contralateral mPFC. 

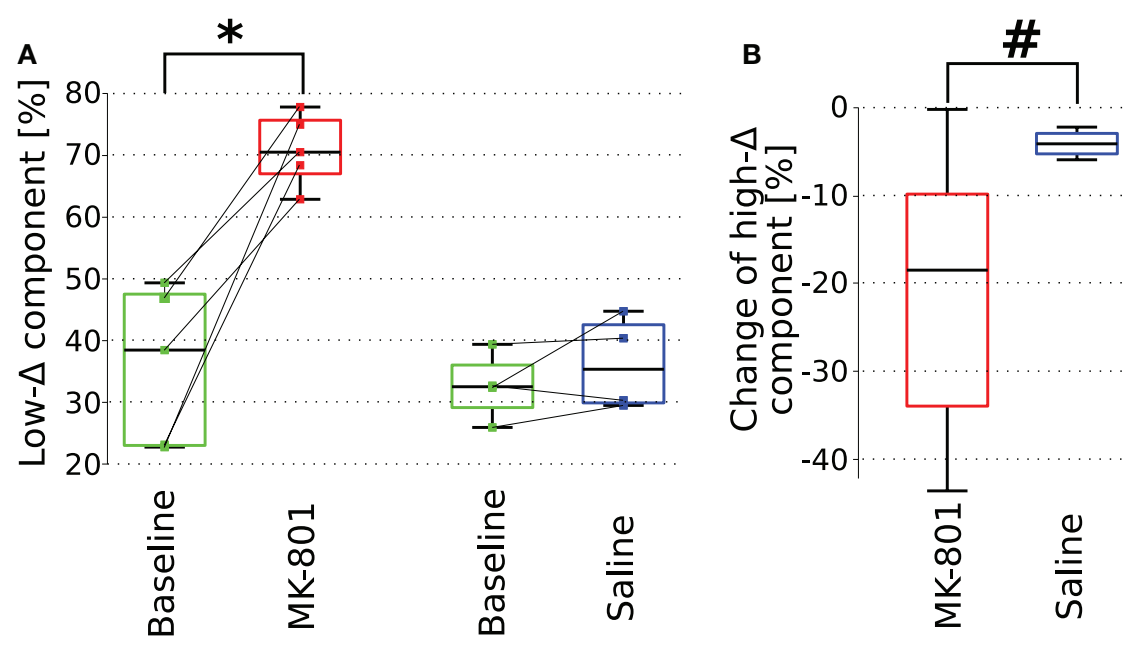

FIGURE 8 | Comparison of LFP oscillation properties following intra-thalamic (MD) microinjection of saline or MK-801. (A) A significant increase in low-delta power after local injection of MK-801 $(p=0.004)$ but not saline into the MD. As noted at Figures 7D and 9D both MK-801 and saline induced a significant decrease in high-delta power, however, as shown here on panel (B) the magnitude of the change following MK-801 is significantly larger ( $p=0.04$, left-tailed $t$-test) than that induced by saline injection.

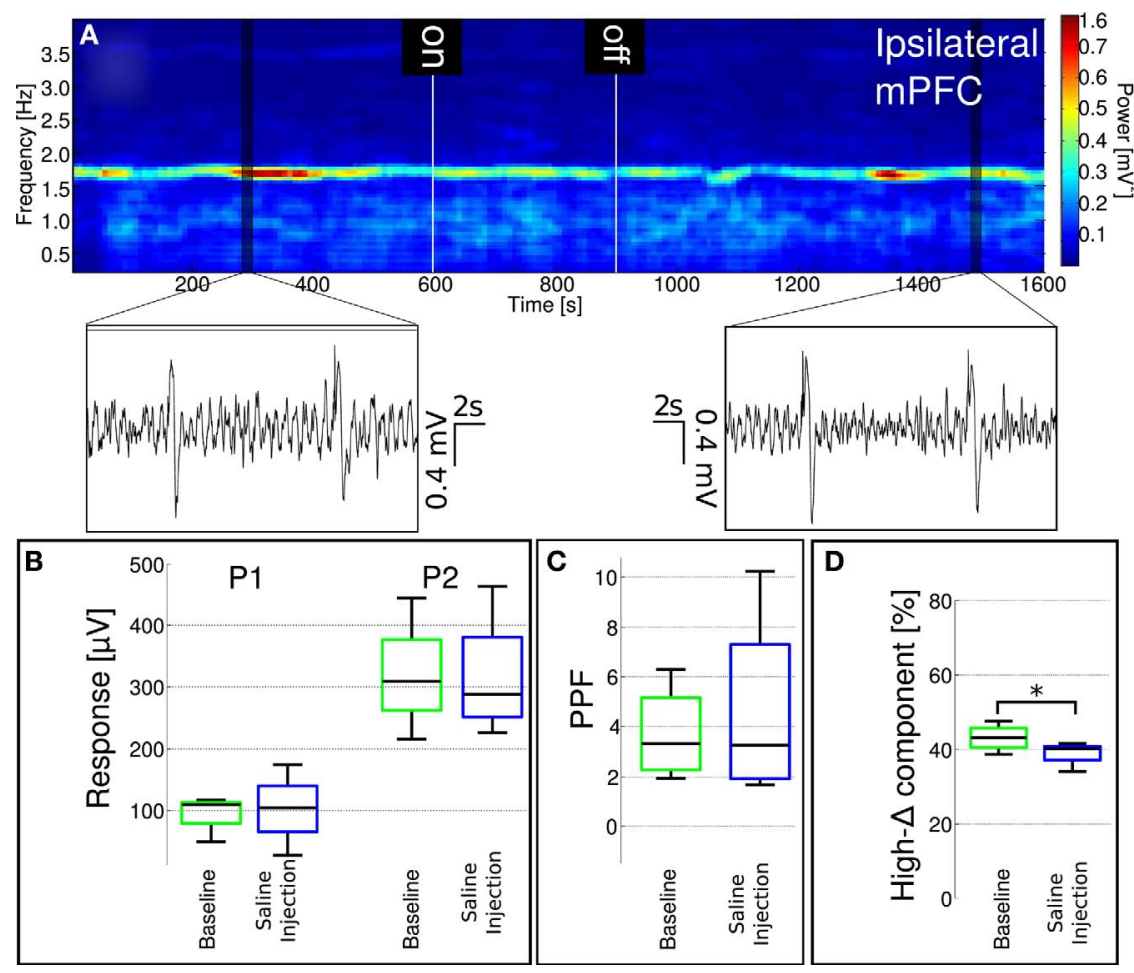

FIGURE 9 | Localized saline administration into the mediodorsal nucleus of the thalamus does not enhance low-delta activity and fails to replicate effects of localized MK-801 administration. (A) A representative spectrogram of ipsilateral mPFC LFP. Insets show characteristic LFP traces from highlighted regions.
(B,C) MD-localized saline injection did not influence paired-pulse facilitation. (D) Ongoing LFP high-delta oscillation power significantly $(p=0.0134)$ decreased after saline injection, however the magnitude of the change was significantly smaller compared to the decreased observed after MK-801 administration (see Figure 8). containing parvalbumin (Xi et al., 2009), innervating pyramidal neurons. However, recent findings have revealed a much more complex picture of neuronal effects of MK-801. Firing activity of widespiking putative pyramidal neurons was suppressed or facilitated in approximately equal proportion, similar to the response of fast-firing putative interneurons by MK-801 in freely moving rats performing cognitive tasks (Christian et al., 2010). Our findings in urethane anesthetized animals indicate a diverse response of cortical neurons 
to MK-801, including excitation. In contrast, it has been reported that local application of PCP inhibits the majority of deep mPFC neurons (Gratton et al., 1987) whereas locally applied MK-801 inhibits or maintains the activity of $\mathrm{mPFC}$ but fails to induce excitation (Jodo et al., 2005). We hypothesize that non-competitive NMDAR antagonists might affect NMDARs on both principal cells and interneurons in a similar fashion and the net effect of NMDAR blockade results from changing the balance of firing in these two populations. A possible explanation for different changes of firing rates seen after NMDAR antagonism in different experimental conditions could be a difference in baseline firing dependent upon behavioral state. For example, during active wakefulness firing rate of interneurons is typically much higher than that of pyramidal cells, while under anesthesia this might not be the case.

Present results together with previous findings indicate that changes in mPFC electrophysiology and function induced by NMDAR antagonists are downstream effects, involving modulation of activity of afferent pathways to mPFC (Lorrain et al., 2003) such as the hippocampus (Jodo et al., 2005) or one or multiple thalamic subregions. Here we are proposing a critical role of subcortical regions, particularly the thalamus, in NMDAR antagonism-induced schizophrenia-like symptoms. In fact, our current findings provide direct evidence for the involvement of the thalamo-cortical projection in MK-801-induced changes in cortical activity. Thus, microinjection of MK-801 targeted into the MD thalamic nucleus, but not into the mPFC, elicited changes reminiscent of systemic administration of the drug, leading to altered relative delta power distribution, and reduced PPF. It is well established that the thalamus plays a critical role in processing and integrating sensory information relayed to the cortex (Steriade et al., 1997) and can regulate the state of information processing in different cortical regions (Mumford, 1991; Hirata and Castro-Alamancos, 2010). A number of thalamic areas have been shown to be affected in schizophrenia (Sharp et al., 2001; Clinton and Meador-Woodruff, 2004; Alelú-Paz and Giménez-Amaya, 2008; Lisman et al., 2010) and the primary brain region where a decrease in cell number has been shown in schizophrenic brains is the MD (Pakkenberg, 1990, 1992, 1993; Popken et al., 2000; Young et al., 2000; Byne et al., 2002). In line with these findings, blockade of NMDARs in the thalamus by MK-801 (Tomitaka et al., 2000) or by PCP (Santana et al., 2011) has been shown to activate and injure principal cells in several cortical regions.

There are differences when comparing our findings in urethane anesthetized animals with previous results in freely moving animals. Firstly, we observed a decrease of action potential generation at the population level, while in freely moving animals MK-801 induced an increase in pyramidal cell firing (Jackson et al., 2004; Homayoun et al., 2005; Lisman et al., 2008). Secondly, burstiness in our experiments increased slightly, however, in freely moving animals a decrease was observed (Jackson et al., 2004). Finally, the LFP amplitude histogram became right-skewed after MK-801 administration, which was interpreted to be due to a more hyperpolarized LFP, possibly resulting from glutamate hypofunction, while in freely moving animals PCP (Moghaddam and Adams, 1998) or ketamine (Lorrain et al., 2003) induced increased glutamate release. Based on the working hypothesis that changes induced by NMDAR antagonists in the $\mathrm{mPFC}$ are downstream effects originating from the thalamus, a possible explanation for the differences observed under urethane anesthesia compared to the freely moving case might lie in the difference between the activity profile of interneuron firing, especially a difference in the activity of thalamic reticular GABAergic neuron firing. Microinjections in our experiments were targeted into the mediodorsal nucleus of the thalamus. A relatively high volume and high dose of MK-801 was applied and the latency of the observed effects were variable. Injection of MK-801 in the same dose and volume into the $\mathrm{mPFC}$ did not elicit changes in cortical oscillation or PPF, indicating a local site of action following MD administration. However, the exact site of action of MK-801 in the thalamus is not certain and the possibility that MK-801 impacts neuronal activity in the thalamic reticular formation cannot be excluded. The differences in thalamic neuron activity between awake and anesthetized animals could explain differences in response to NMDAR antagonism in these respective paradigms. For example, thalamic reticular neurons are depolarized in awake animals (Pinault, 2004), whereas they are hyperpolarized under urethane anesthesia (Yen and Shaw, 2003; Pinault, 2004). Consequently, use-dependent NMDAR antagonists would impact neuronal activity differently depending on the vigilant state. While in freely moving animals antagonism on interneurons' NMDARs is more pronounced, in anesthetized animals NMDARs on principal cells might primarily be blocked, resulting in differences in electrophysiological measures.

As referred to before, it is unclear whether activity of all principal neurons are increased after NMDAR antagonism even in awake rats, or if the main action of these drugs lies with their disruptive effects on complex neuronal circuitries. Interestingly enough, using proton magnetic resonance spectroscopy Lutkenhoff et al. (2010) recently found that glutamate was significantly lower in the mesial prefrontal gray matter of patients with schizophrenia and unaffected co-twins than in healthy controls. This also supports a more diverse pathophysiology of schizophrenia than an enhanced glutamate transmission and a reduced feed-forward inhibition of principal neurons as has been suggested by previous models. Furthermore, if the above speculation is true it could have an impact on the timing of administration of drugs, which directly (ketamine, mementine) or indirectly (AMPA potentiators) modulate NMDARmediated neurotransmission; these drugs might influence brain activity differently depending on the vigilant state.

Taken together, present results show that local application of the use-dependent NMDAR antagonist MK-801 into the mediodorsal nucleus of the thalamus modulates ongoing field oscillation and concomitantly PPF in the mPFC in urethane anesthetized rats. Based on these findings we hypothesize that disruptive effects of NMDAR antagonists on cognitive function are exerted primarily in the thalamus and consequently via the thalamo-cortical circuitry.

\section{ACKNOWLEDGMENTS}

This work was supported by Pfizer Global Research and Development, Groton, CT, USA, and carried out as part of the Innovative Medicines Initiative Joint Undertaking (IMI) under Grant Agreement No. 115008. IMI is a public-private partnership between the European Union and the European Federation of Pharmaceutical Industries and Associations. During preparation of this work, Tamás Kiss was on sabbatical leave from the KFKI Research Institute for Particle and Nuclear Physics of the Hungarian Academy of Sciences. 


\section{REFERENCES}

Alelú-Paz, R., and Giménez-Amaya, J. M. (2008). The mediodorsal thalamic nucleus and schizophrenia. J. Psychiatry Neurosci. 33, 489-498.

Amzica, F., and Steriade, M. (1998). Electrophysiological correlates of sleep delta waves. Electroencephalogr. Clin. Neurophysiol. 107, 69-83.

Breier, A., Malhotra, A. K., Pinals, D. A., Weisenfeld, N. I., and Pickar, D. (1997). Association of ketamine-induced psychosis with focal activation of the prefrontal cortex in healthy volunteers. Am. J. Psychiatry 154, 805-811.

Buccafusco, J. J., and Terry, A. V. Jr. (2009). A reversible model of the cognitive impairment associated with schizophrenia in monkeys: potential therapeutic effects of two nicotinic acetylcholine receptor agonists. Biochem. Pharmacol. 78, 852-862.

Byne, W., Buchsbaum, M. S., Mattiace, L. A., Hazlett, E. A., Kemether, E., Elhakem, S. L., Purohit, D. P., Haroutunian, V., and Jones, L. (2002). Postmortem assessment of thalamic nuclear volumes in subjects with schizophrenia. Am. J. Psychiatry 159, 59-65.

Christian, E. P., Snyder, D., Gurley, D., Song, W., Leiser, S. C., Doherty, J. J., and Quirk, M. C. (2010). Simultaneous Monitoring of Prefrontal Neuronal Firing, Combined with EEG Translational Biomarkers During Administration OfSubanesthetic Doses of MK801 in Behaving Rat. Program No. 817.13 Neuroscience Meeting Planner. Society for Neuroscience, San Diego, CA. [Online].

Clinton, S. M., and Meador-Woodruff, J. H. (2004). Thalamic dysfunction in schizophrenia: neurochemical, neuropathological, and in vivo imaging abnormalities. Schizophr. Res. 69, 237-253.

Delorme, A., and Makeig, S. (2004). EEGLAB: an open source toolbox for analysis of single-trial EEG dynamics including independent component analysis. J. Neurosci. Methods 134, 9-21.

Freed, W. J., Weinberger, D. R., Bing, L. A., and Wyatt, R. J. (1980). Neuropharmacological studies of phencyclidine (PCP)-induced behavioral stimulation in mice. Psychopharmacology 71, 291-297.

Gratton, A., Hoffer, B. J., and Freedman, R. (1987). Electrophysiological effects of phencyclidine in the medial prefrontal cortex of the rat. Neuropharmacology 26, 1275-1283.

Gruber,A. J., Calhoon, G. G., Shusterman, I., Schoenbaum, G., Roesch, M. R., and O'Donnell, P. (2010). More is less: a disinhibited prefrontal cortex impairs cognitive flexibility. J. Neurosci. 30, 17102-17110.

Gunduz-Bruce, H. (2009). The acute effects of NMDA antagonism: from the rodent to the human brain. Brain Res. Rev. 60, 279-286.

Harris, K. D. A., Henze, D., Csicsvári, J., Hirase, H., and Buzsáki, G. (2000). Accuracy of tetrode spike separation as determined by simultaneous intracellular and extracellular measurements. J. Neurophysiol. 84, 401-414.

Harrison, P. J., and Owen, M. J. (2003). Genes for schizophrenia? Recent findings and their pathophysiological implications. Lancet 361, 417-419.

Harrison, P. J., and West, V. A. (2006). Six degrees of separation: on the prior probability that schizophrenia susceptibility genes converge on synapses, glutamate and NMDA receptors. $\mathrm{Mol}$. Psychiatry 11, 981-983.

Heale, V., and Harley, C. (1990). MK-801 and AP5 impair acquisition, but not retention, of the Morris milk maze. Pharmacol. Biochem. Behav. 36, 145-149.

Hirata, A., and Castro-Alamancos, M. A (2010). Neocortex network activation and deactivation states controlled by the thalamus. J. Neurophysiol. 103, 1147-1157.

Homayoun, H., Jackson, M. E., and Moghaddam, B. (2005). Activation of metabotropic glutamate $2 / 3$ receptors reverses the effects of NMDA receptor hypofunction on prefrontal cortex unit activity in awake rats. J. Neurophysiol. 93, 1989-2001.

Homayoun, H., and Moghaddam, B. (2007). NMDA receptor hypofunction produces opposite effects on prefrontal cortex interneurons and pyramidal neurons. J. Neurosci. 27, 11496-11500.

Jackson, M. E., Homayoun, H., and Moghaddam, B. (2004). NMDA receptor hypofunction produces concomitant firing rate potentiation and burst activity reduction in the prefrontal cortex. Proc. Natl. Acad. Sci. U.S.A. 101, 8467-8472.

Javitt, D. C., Spencer, K. M., Thaker, G. K., Winterer, G., and Hajós, M. (2008). Neurophysiological biomarkers for drug development in schizophrenia. Nat. Rev. Drug Discov. 7, 68-83.

Jentsch, J. D., and Roth, R. H. (1999). The neuropsychopharmacology of phencyclidine: from NMDA receptor hypofunction to the dopamine hypothesis of schizophrenia. Neuropsychopharmacology 20, 201-225.

Jodo, E., Suzuki, Y., Katayama, T., Hoshino, K.-Y., Takeuchi, S., Niwa, S-I., and Kayama, Y. (2005). Activation of medial prefrontal cortex by phencyclidine is mediated via a hippocampo-prefrontal pathway. Cereb. Cortex 15, 663-669.

Kantrowitz, J. T., and Javitt, D. C. (2010) $\mathrm{N}$-methyl-d-aspartate (NMDA) receptor dysfunction or dysregulation: the final common pathway on the road to schizophrenia? Brain Res. Bull. 83, 108-121.

Kargieman, L., Santana, N., Mengod, G., Celada, P., and Artigas, F. (2007) Antipsychotic drugs reverse the disruption in prefrontal cortex function produced by NMDA receptor blockade with phencyclidine. Proc. Natl. Acad. Sci. U.S.A. 104, 14843-14848.

Kiss, T., Hoffmann, W. E., and Hajós, M. (2011). Delta oscillation and shortterm plasticity in the rat medial prefrontal cortex: modelling NMDA hypofunction of schizophrenia. Int J. Neuropsychopharmacol. 14, 17-28.

Knable, M. B., and Weinberger, D. R. (1997). Dopamine, the prefrontal cortex and schizophrenia. $J$ Psychopharmacol. 11, 123-131.

Krystal, J. H., Karper, L. P., Seibyl, J. P., Freeman, G. K., Delaney, R., Bremner, J. D., Heninger, G. R., Bowers, M B. Jr., and Charney, D. S. (1994). Subanesthetic effects of the noncompetitive NMDA antagonist, ketamine in humans. Psychotomimetic, perceptual, cognitive, and neuroendocrine responses. Arch. Gen. Psychiatry 51, 199-214.

Lahti, A. C., Holcomb, H. H., Medoff, D. R., and Tamminga, C. A. (1995a) Ketamine activates psychosis and alters limbic blood flow in schizophrenia. Neuroreport 6, 869-872.

Lahti, A. C., Koffel, B., LaPorte, D. and Tamminga, C. A. (1995b). Subanesthetic doses of ketamine stimulate psychosis in schizophrenia. Neuropsychopharmacology 13, 9-19.

Lidierth, M. (2009). sigTOOL: a MATLAB-based environment for sharing laboratory-developed software to analyze biological signals. $J$. Neurosci. Methods 178, 188-196.

Lisman, J. E., Coyle, J. T., Green, R. W. Javitt, D. C., Benes, F. M., Heckers, S., and Grace, A.A. (2008). Circuit-based framework for understanding neurotransmitter and risk gene interactions in schizophrenia. Trends Neurosci. 31 234-242.

Lisman, J. E., Pi, H. J., Zhang, Y., and Otmakhova, N.A. (2010). A thalamohippocampal-ventral tagmental area loop may produce the positive feedback that underlies the psychotic break in schizophrenia. Biol. Psychiatry 68, 17-24.

Lorrain, D. S., Baccei, C. S., Bristow, L. J., Anderson, J. J., and Varney, M. A. (2003). Effects of ketamine and N-Methyl-D-Aspartate on glutamate and dopamine release in the rat prefrontal cortex: modulation by a group II selective metabotropic glutamate receptor agonist LY379268. Neuroscience 117, 697-706.

Luby, E. D., Cohen, B. D., Rosenbaum, G., Gottlieb, J. S., and Kelley, R. (1959). Study of a new schizophrenomimetic drug; sernyl. A.M.A. Arch. Neurol. Psychiatry 81, 363-369.

Lutkenhoff, E. S., van Erp, T. G., Thomas, M. A., Therman, S., Manninen, M. Huttunen, M. O., Kaprio, J., Lnnqvist, J., O’Neill, J., and Cannon, T. D. (2010). Proton MRS in twin pairs discordant for schizophrenia. Mol. Psychiatry 15, 308-318.

Malhotra,A. K., Pinals, D.A., Weingartner, H., Sirocco, K., Missar, C. D., Pickar, D. and Breier, A. (1996). NMDA receptor function and human cognition: the effects of ketamine in healthy volunteers. Neuropsychopharmacology 14 , 301-307.

Mansbach, R. S., and Geyer, M. A. (1989). Effects of phencyclidine and phencyclidine biologs on sensorimotor gating in the rat. Neuropsychopharmacology 2, 299-308.

Marek, G. J., Behl, B., Bespalov, A. Y., Gross, G., Lee, Y., and Schoemaker, H. (2010). Glutamatergic (N-methylD-aspartate receptor) hypofrontality in schizophrenia: too little juice or a miswired brain? Mol. Pharmacol. 77, 317-326.

Miller, C. L., Bickford, P. C., LuntzLeybman, V., Adler, L. E., Gerhardt, G. A., and Freedman, R. (1992). Phencyclidine and auditory sensory gating in the hippocampus of the rat. Neuropharmacology 31, 1041-1048.

Moghaddam, B. (2003). Bringing order to the glutamate chaos in schizophrenia. Neuron 40, 881-884.

Moghaddam, B., and Adams, B.W. (1998). Reversal of phencyclidine effects by a group II metabotropic glutamate receptor agonist in rats. Science 281, 1349-1352.

Mumford, D. (1991). On the computational architecture of the neocortex: I. The role of the thalamocortical loop. Biol. Cybern. 65, 135-145.

Newcomer, J. W., Farber, N. B., JevtovicTodorovic, V., Selke, G., Melson, A. K., Hershey, T., Craft, S., and Olney, J. W. (1999). Ketamine-induced NMDA receptor hypofunction as a model of memory impairment and psychosis. Neuropsychopharmacology 20, 106-118.

Olbrich, H. M., Valerius, G., Rüsch, N., Buchert, M., Thiel, T., Hennig, J., Ebert, D., and Van Elst, L. T. (2008). Frontolimbic glutamate alterations in first episode schizophrenia: evidence from a magnetic resonance 
spectroscopy study. World J. Biol. Psychiatry 9, 59-63.

Pakkenberg, G. (1990). Pronounced reduction of total neuron number in mediodorsal thalamic nucleus and nucleus accumbens in schizophrenics. Arch. Gen. Psychiatry 47, 1023-1028.

Pakkenberg, G. (1992). The volume of the mediodorsal thalamic nucleus in treated and untreated schizophrenics. Schizophr. Res. 7, 95-100.

Pakkenberg, G. (1993). Leucotomized schizophrenicslose neurons in the mediodorsal thalamic nucleus. Neuropathol. Appl. Neurobiol. 19, 373-380.

Paxinos, G., and Watson, C. (1986). The Rat Brain in Stereotaxic Coordinates, 2nd Edn. Sydney: Academic Press.

Pinault, D. (2004). The thalamic reticular nucleus: structure, function and concept. Brain Res. Rev. 46, 1-31.

Popken, G. J., Bunney, W. E. Jr., Potkin, S. G., and Jones, E. G. (2000). Subnucleusspecific loss of neurons in medial thalamus of schizophrenics. Proc. Natl. Acad. Sci. U.S.A. 97, 9276-9280.

Quiroga, Q., Nádasdy, Z., and Ben-Shaul, Y. (2004). Unsupervised spike detection and sorting with wavelets and superparamagnetic clustering. Neural. Comput. 16, 1661-1687.

R Development Core Team. (2008). R: A Language and Environment for Statistical Computing. Vienna: R Foundation for Statistical Computing.

Roberts, B. M., Seymour, P. A., Schmidt, C. J., Williams, G. V., and Castner, S.A. (2010a). Amelioration of ketamineinduced working memory deficits by dopamine D1 receptor agonists. Psychopharmacology 210, 407-418.

Roberts, B. M., Shaffer, C. L., Seymour, P. A., Schmidt, C. J., Williams, G. V., and Castner, S. A. (2010b). Glycine transporter inhibition reverses ketamine-induced working memory deficits. Neuroreport 21, 390-394.
Roberts, B. M., Holden, D. E., Shaffer, C. L., Seymour, P. A., Menniti, F. S., Schmidt, C. J., Williams, G. V., and Castner, S. A. (2010c). Prevention of ketamine-induced working memory impairments by AMPA potentiators in a nonhuman primate model of cognitive dysfunction. Behav. Brain Res. 212, 41-48.

Santana, N., Troyano, E., Mengod, G., Celada, P., and Artigas, F. (2011). Activation of thalamocortical networks by NMDA receptor antagonist phencyclidine. Reversal by clozapine. Biol. Psychiatry, doi:10.1016/j.biopsych.2010.10.030

Sebban, C., Tesolin-Decros, B., CiprianOllivier, J., Perret, L., and Spedding, M. (2002). Effects of phencyclidine (PCP) and MK 801 on the EEGq in the prefrontal cortex of conscious rats; antagonism by clozapine, and antagonists of AMPA-, alpha(1)- and 5-HT(2A)receptors. Br. J. Pharmacol. 135, 65-78.

Sharp, F. R., Tomitaka, M., Bernaudin, M., and Tomitaka, S. (2001). Psychosis: pathological activation of limbic thalamocortical circuits by psychomimetics and schizophrenia? Trends Neurosci. 24, 330-334.

Steriade, M., Jones, E. G., and McCormick, D. A. (1997). Thalamus: Organization and Function. Amsterdam: Elsevier.

Steriade, M., McCormick, D. A., and Sejnowski, T. J. (1993). Thalamocortical oscillations in the sleeping and aroused brain. Science 262, 679-685.

Suzuki, Y., Jodo, E., Takeuchi, S., Niwa, S., and Kayama, Y. (2002). Acute administration of phencyclidine induces tonic activation of medial prefrontal cortex neurons in freely moving rats. Neuroscience 114, 769-779.

Taffe, M. A., Davis, S. A., Yuan, J., Schroeder, R., Hatzidimitriou, G., Parsons, L. H., Ricaurte, G. A., and
Gold, L. H. (2002). Cognitive performance of MDMA-treated rhesus monkeys: sensitivity to serotonergic challenge. Neuropsychopharmacology 27, 993-1005.

Théberge, J., Al-Semaan, Y., Williamson, P. C., Menon, R. S., Neufeld, R. W., Rajakumar, N.,Schaefer, B., Densmore, M., and Drost, D. J. (2003). Glutamate and glutamine in the anterior cingulate and thalamus of medicated patients with chronic schizophrenia and healthy comparison subjects measured with 4.0-T proton MRS. Am. J. Psychiatry 160, 2231-2233.

Tomitaka, S., Tomitaka, M., Tolliver, B. K., and Sharp, F. R. (2000). Ilateral blockade of NMDA receptors in anterior thalamus by dizocilpine (MK-801) injures pyramidal neurons in rat retrosplenial cortex. Eur. J. Neurosci. 12, 1420-1430.

Tsai, G., Passani, L.A.,Slusher, B. S., Carter, R., Baer, L., Kleinman, J. E., and Coyle, J. T. (1995). Abnormal excitatory neurotransmitter metabolism in schizophrenic brains. Arch. Gen. Psychiatry 52, 829-836.

van Elst, L. T., Valerius, G., Büchert, M. Thiel, T., Rüsch, N., Bubl, E., Hennig, J.,Ebert, D., and Olbrich, H.M. (2005) Increased prefrontal and hippocampal glutamate concentration in schizophrenia: evidence from a magnetic resonance spectroscopy study. Biol. Psychiatry 58, 724-730.

Verma, A., and Moghaddam, B. (1996). NMDA receptor antagonists impair prefrontal cortex function as assessed via spatial delayed alternation performance in rats: modulation by dopamine. J. Neurosci. 16, 373-379.

Winn, P. (1994). Schizophrenia research moves to the prefrontal cortex. Trends Neurosci. 17, 265-268.

Xi, D., Zhang, W., Wang, H. X., Stradtman, G. G., and Gao, W. J.
(2009). Dizocilpine (MK-801) induces distinct changes of N-methyl-Daspartic acid receptor subunits in parvalbumin-containing interneurons in young adult rat prefrontal cortex. Int. J. Neuropsychopharmacol. 12, 1395-1408.

Yen, C.-T., and Shaw, F.-Z. (2003). Reticular thalamic responses to nociceptive inputs in anesthetized rats. Brain Res. 968, 179-191.

Young, K. A., Manaye, K. F., Liang, C., Hicks, P. B., and German, D. C. (2000). Reduced number of mediodorsal and anterior thalamic neurons in schizophrenia. Biol. Psychiatry 47, 944-953.

Conflict of Interest Statement: Tamás Kiss, William E. Hoffmann, Liam Scott, Thomas T. Kawabe, Anthony J. Milici, and Mihály Hajós are full time employees of Pfizer Inc., Erik A. Nilsen is an employee of Blackrock Microsystems.

Received: 03 December 2010; accepted: 22 March 2011; published online: 04 April 2011.

Citation: Kiss T, Hoffmann WE, Scott L, Kawabe TT, Milici AJ, Nilsen EA and Hajos M (2011) Role of thalamic projection in NMDA receptor-induced disruption of cortical slow oscillation and short-term plasticity. Front. Psychiatry 2:14. doi: 10.3389/fpsyt.2011.00014

This article was submitted to Frontiers in Schizophrenia, a specialty of Frontiers in Psychiatry.

Copyright $\odot 2011$ Kiss, Hoffmann, Scott, Kawabe, Milici, Nilsen and Hajós. This is an open-access article subject to a nonexclusive license between the authors and Frontiers Media SA, which permits use, distribution and reproduction in other forums, provided the original authors and source are credited and other Frontiers conditions are complied with. 